\title{
Optimization of a multi-constraint transport problem using a heuristic approach
}

\author{
Ngnassi Djami Aslain Brisco ${ }^{1,}{ }^{*}$, Nzié Wolfgang ${ }^{1,2}$ and Doka Yamigno Serge ${ }^{3}$ \\ ${ }^{1}$ Department of Fundamental Sciences and Engineering Techniques, Chemical Engineering and Mineral Industries School, \\ University of Ngaoundere, Cameroon. \\ 2 Department of Mechanical Engineering, National Advanced School of Agro-Industrial Sciences, University of Ngaoundere, \\ Cameroon. \\ ${ }^{3}$ Department of Physics, Faculty of Science, University of Ngaoundere, Cameroon.
}

Global Journal of Engineering and Technology Advances, 2022, 10(01), 001-021

Publication history: Received on 05 May 2021; revised on 25 November 2021; accepted on 02 January 2022

Article DOI: https://doi.org/10.30574/gjeta.2021.10.1.0158

\begin{abstract}
A Linear transport problem can be defined as the action of transporting products from " $m$ origins" (or units) to " $n$ destinations" (or customers) at the lowest cost. So the solution to a transportation problem is to organize the transportation in such a way as to minimize its cost. The objective of this paper is to determine the quantity sent from each source (origin) to each destination while minimizing transport costs. Achieving this objective requires a methodology which consists in deploying an algorithm whose purpose is the search for an optimal solution, based on an initial solution. The application is made on a factory producing mechanical parts.
\end{abstract}

Keywords: Cost; Optimization; Linear programming problem; Heuristic method

\section{Introduction}

The transport problem was first formulated by Hitchcock [1] and later discussed in detail [2]. Important developments were made in this field during the Second World War by the Russian mathematician and economist [3]. The transport problem consists in minimizing the cost of transport from the different origins to the different destinations while respecting the constraints of availability and demand [4].

The formulation of linear programming and the associated systematic method of solving were first given by Dantzig [5]. Recent approaches have been respectively given by several authors $[6,7,8,9]$.

The transport problem is a linear problem which can be represented in the form of a graph and which can be solved using different heuristic methods of solving linear problems, which will be the subject of the remainder of this paper.

\section{General formulation of the transport problem}

Products must be transported from $m$ deposit centers (units) to $n$ consumption centers (customers). The transport of a product from origin $i$ to destination $j$ has a $\operatorname{cost} c_{i j}$, and it is assumed that the availability, of products from unit $i$ and the demand for products from customer $j$ are known.

\footnotetext{
${ }^{*}$ Corresponding author: Ngnassi Djami Aslain Brisco

Department of Fundamental Sciences and Engineering Techniques, Chemical Engineering and Mineral Industries School, University of Ngaoundere, Cameroon.

Copyright (C) 2022 Author(s) retain the copyright of this article. This article is published under the terms of the Creative Commons Attribution Liscense 4.0.
} 


\subsection{Decision variables}

The variables of the linear programming model of the transport problem are natural numbers representing products transported from a source to a destination.

We denote by $x_{i j}$ the quantity to be transported from $i$ to $j \forall i, j \in\{1, \ldots, m\} \times\{1, \ldots, n\}$.

The transport problem consists in determining the quantities $x_{i j}$ to transport so that the total transport cost $\sum_{i=1}^{m} \sum_{j=1}^{n} c_{i j} x_{i j}$ is minimal.

\subsection{Constraints}

Constraints are the conditions that compel demand to be met and availability to be exhausted. They are given below:

- The stock of product must be sold (the total quantity of products starting from $i$ is equal to the availability), that is : $\sum_{j=1}^{n} x_{i j}=a_{i}, i=1, \ldots, m$;

- The demand must be satisfied (the total quantity of products received by $j$ is equal to the demand), that is to say: $\sum_{i=1}^{m} x_{i j}=b_{j}, j=1, \ldots, n$;

- To solve the problem, it is imperative that the global demand is equal to the global availability: $\sum_{i=1}^{m} a_{i}=\sum_{j=1}^{n} b_{j}$;

- In the case of an unbalanced transport problem (where the previous constraint is not respected), for example if $\sum_{i=1}^{m} a_{i} \prec \sum_{j=1}^{n} b_{j}$, it would be necessary to create a fictitious source (or a line) for which all the transport costs are zero and have a demand $b=\sum_{j=1}^{n} b_{j}-\sum_{i=1}^{m} a_{i}$;

- We must respect the non-negativity of quantities: $x_{i j} \geq 0, \forall i, j \in\{1, \ldots, m\} \times\{1, \ldots, n\}$.

\subsection{Objective function}

Based on the work of several authors in the literature, such as that of $[10,11,12]$ we define the mathematical formulation of the objective function by equation 1 , for the general resolution of transport problems.

Minimize $\mathrm{z}=\sum_{i=1}^{m} \sum_{j=1}^{n} c_{i j} x_{i j}$

Subject to $\left\{\begin{array}{l}\sum_{j=1}^{n} x_{i j}=a_{i}, i=1,2, \ldots, m \\ \sum_{i=1}^{m} x_{i j}=b_{j}, \mathrm{j}=1,2, \ldots, n \\ \sum_{i=1}^{m} a_{i}=\sum_{j=1}^{n} b_{j} \\ x_{i j} \geq 0, \text { for all } i \text { and } j\end{array}\right.$ 


\section{Solving the transport problem}

Solving a linear programming problem involves two essential steps: first finding an initial basic solution, then finding the optimal solution from the basic solution. By synthesizing the work of $[4,10,12,13,14,15,16,17,18,19,20,21]$ who approach the methods of resolution of the transport problem, we propose an algorithm of resolution of these problems in Figure1. We then describe the different stages of this algorithm.

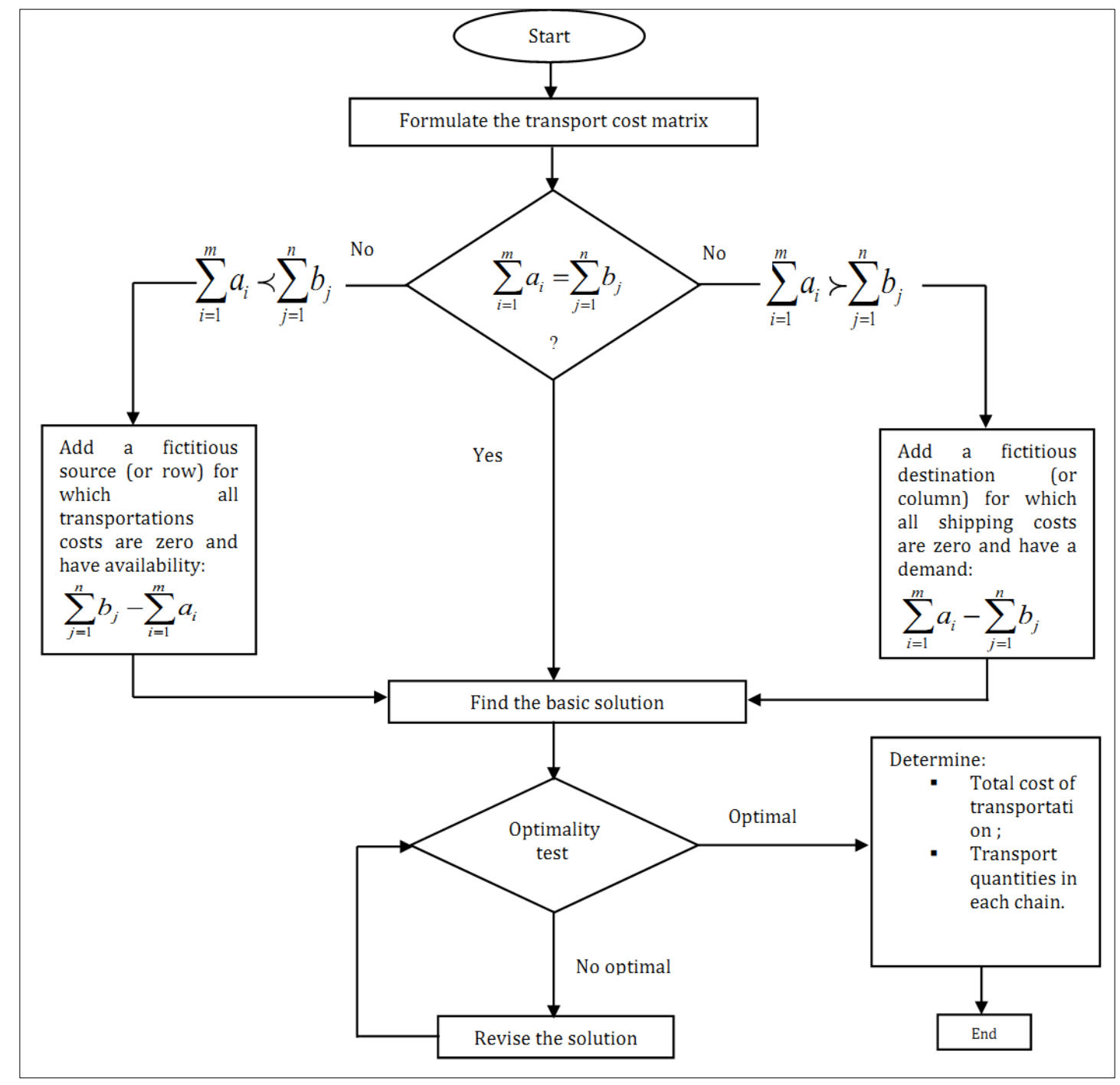

Figure 1 General algorithm for solving a transport problem

\subsection{Formulation of the problem in matrix form}

Table 1 Matrix formulation of a balanced transport problem

\begin{tabular}{|c|c|c|c|c|}
\hline$c_{11}$ & $c_{12}$ & $\cdots$ & $c_{1 n}$ & $a_{1}$ \\
\hline$c_{21}$ & $c_{22}$ & $\cdots$ & $c_{2 n}$ & $\boldsymbol{a}_{2}$ \\
\hline$\vdots$ & $\vdots$ & $\cdots$ & $\vdots$ & $\vdots$ \\
\hline$c_{\boldsymbol{m} 1}$ & $\boldsymbol{c}_{\boldsymbol{m} 2}$ & $\cdots$ & $\boldsymbol{c}_{\boldsymbol{m n}}$ & $\boldsymbol{a}_{\boldsymbol{m}}$ \\
\hline $\boldsymbol{b}_{\mathbf{1}}$ & $\boldsymbol{b}_{\mathbf{2}}$ & $\ldots$ & $\boldsymbol{b}_{\boldsymbol{n}}$ & $\sum_{i=1}^{m} a_{i}=\sum_{j=1}^{n} b_{j}$ \\
\hline
\end{tabular}


The formulation of the transport problem is similar to the formulation of the linear programming problem. Here, the objective function is the total cost of transportation and the constraints are the supply and demand available at each source and destination, respectively (see equation 1 ).

The general formulation of a balanced transport problem in matrix form is given in Table 1.

The graph representing the transport problem (transport network), allowing a general deduction of the matrix formulation, is given by Figure 2



Figure 2 Transport network

\subsection{Obtain a first feasible basic solution}

This initial basic solution can be obtained by using one of the following heuristics:

- The North-West Corner method;

- The Minimum Cost method ;

- The Vogel approximation method.

The solution obtained by one of the above methods must meet the following conditions:

The solution must be feasible, that is, it must meet all the constraints of supply and demand;

The number of positive assignments (allocated cells) must be equal to, where $m$ is the number of rows and $n$ is the number of columns.

The solution which satisfies the above-mentioned conditions and having exactly $(m-1)(n-1)$ zero fluxes is called a non-degenerate basic solution.

\subsubsection{The North-West Corner method}

The North-West Corner method is an easy method but it does not make economic sense, since it consists in assigning to the North-West Corner of each grid the maximum possible quantity without worrying about the importance of the cost [22].

This method is deployed in four stages:

\section{Step 1}

Locate the cell $(p ; q)$ which is in the North-West Corner that is to say at the top left, of the non-eliminated part of the transport table. 


\section{Step 2}

Send the maximum units for the cell $(p ; q)$. Thus $x_{p q}$ is initialized as being the $\min \left\{a_{p} ; b_{q}\right\}$. Adjust $a_{p}$ and $b_{q}$ then and, taking into account the $x_{p q}$ unit to be shipped. Let us express this sentence using equalities $x_{p q}=\min \left\{a_{p} ; b_{q}\right\}$.

The fitted values of $a_{p}$ or $b_{q}$ are given by equation 2 .

$$
\left\{\begin{array}{l}
a_{p}^{\prime}=a_{p}-x_{p q} \\
b_{p}^{\prime}=b_{p}-x_{p q}
\end{array}\right.
$$

At the end of this step, either $a_{p}^{\prime}$ or $b_{q}^{\prime}$ is zero, or both.

\section{Step 3}

- If $a_{p}^{\prime}=0$ and $b_{q}^{\prime} \succ 0$, it means that the origin $p$ has been "emptied". We must therefore eliminate line $p$ from the table.

- If $b_{q}^{\prime}=0$ and $a_{p}^{\prime} \succ 0$, it means that the destination $q$ is completely satisfied and that there are products left in unit $p$. It is therefore necessary to eliminate column $q$ from the table.

- If $a_{p}^{\prime}=0$ and $b_{q}^{\prime}=0$, we are in a degenerate case. Row $p$ is then eliminated, unless it is the only remaining row in the table, in which case column $q$ must be eliminated.

\section{Step 4}

- If there is a total of two or more rows and columns not yet cleared, go back to step 1.

- If there is only one row not deleted from the table, the initial basic feasible solution is determined by the values in bold (see case study).

\subsubsection{The Minimum Cost method}

The Minimum Cost method is a method for calculating a basic feasible solution to a transport problem where the basic variables are chosen according to the unit cost of transport. The Minimum Cost method finds a better starting solution by focusing on the cheapest transport costs [23].

This method differs from the previous one only in the criterion applied in step 1, set out here, steps 2, 3 and 4 remaining the same.

\section{Step 1}

Identify the cell $(p ; q)$ such that the $\operatorname{cost} c_{p q}$ is the smallest cost in the table.

However, it is important to make the following remarks:

- If there are two or more minimum costs, select the row and column corresponding to the lower numbered row;

- If they appear in the same row, select the bottom numbered column.

\subsubsection{Vogel's Approximation method}

The Vogel Approximation method is also known as the Balas-Hammer heuristic, or the maximum deference method, or the unit penalty method, or the successive maximum regrets method. This method is based on the calculation of regrets. The regret associated with a row or column is the difference between the minimum cost and the next higher cost in that row or column. This is a measure of the priority to be given to the transports of that row or that column, because a large regret corresponds to a large penalty if one does not use the minimum cost route [22]. 
In general, Vogel's method provides a solution very close to the optimum. The number of base changes necessary to arrive at an optimal solution is low (it even happens quite frequently that the solution given by this rule is optimal) [23]. The steps of the Vogel Approximation Algorithm are described as follows:

\section{Step 1}

Calculate the deferences $\Delta_{\ell}$ (difference between the minimum cost and the one immediately higher on a row) and $\Delta_{c}$ (difference between the minimum cost and the one immediately higher on a column).

\section{Step 2}

Select the row or column having the $\Delta_{\ell}$ or $\Delta_{c}$ maximum.

\section{Step 3}

Choose the lowest cost in this row or column.

\section{Step 4}

Allocate to the corresponding cell $(p ; q)$ the maximum possible transportable material so as to saturate either the destination or the availability $\left(x_{p q}=\min \left\{a_{p} ; b_{q}\right\}\right)$.

\section{Step 5}

Calculate the residual quantity either in demand or in availability (use relation 2).

\section{Step 6}

Eliminate the row or column having its availability or demand satisfied.

\section{Step 7}

If the number of rows or columns $>2$, then go back to step 1. Otherwise, assign the remaining quantities to the cells in the row not deleted.

\subsection{Testing the initial base solution for optimality}

The frequently used method is the Stepping-Stone heuristic. Instead, we will use its modified version called "Modified Distribution method", in which mathematical equations replace chains of substitutions, and given that it is more practical [24].

To apply the Modified Distribution method, we first start with the base solution generated by one of the methods stated above (methods of generating an initial solution). Next, we calculate a value $u_{i}$ for each row $i$ and $v_{j}$ for each column $j$ in the transport table (transport matrix).

The steps of the Modified Distribution method are as follows:

\section{Step 1}

To calculate the $u_{i}$ and $v_{j}$ values for each row and each column, reduce the equations: $u_{i}+v_{j}=c_{i j}$.

\section{Step 2}

After all the equations have been written, set one of the two variables $u_{i}$ or $v_{j}$ to zero, and solve the system of equations for all the values $u_{i}$ and $v_{j}$.

\section{Step 3}

Calculate the improvement index for each cell not used by the formula $\Delta_{i j}=c_{i j}-u_{i}-v_{j}$. 


\section{Step 4}

Transfer as much as possible to the cell with the most negative $\Delta_{i j}$ by creating a cycle that meets the demand and availability of each row.

\section{Step 5}

Repeat steps 1 to 4 until there is no negative $\Delta_{i j}$.

\section{Step 6}

Calculate the total cost by multiplying each allowance $\left(x_{i j}\right)$ by its specific cost $\left(c_{i j}\right)$.

\section{Application}

We consider a factory for the production of mechanical parts, comprising three production units and four delivery points (customers). The transport problem materializing the different production capacities per unit, the demands of each customer and the unit costs of transporting material from one unit to a customer is given in Figure 3.



Figure 3 Transport network modeling the case study

The objective of this part is to bring out the optimal transport network, so as to meet supply and demand.

\subsection{Formulate the transport cost matrix}

The formulation of the previous transport problem in matrix form is given in Table 2 .

Table 2 The transport cost matrix of the case study

\begin{tabular}{|c|c|c|c|c|c|}
\hline Origin Destination & $\mathbf{1}$ & $\mathbf{2}$ & $\mathbf{3}$ & $\mathbf{4}$ & Supply \\
\hline 1 & 25 & 18 & 17 & 15 & 350 \\
\hline 2 & 24 & 19 & 13 & 11 & 350 \\
\hline 3 & 22 & 14 & 12 & 10 & 400 \\
\hline Demand & 300 & 300 & 250 & 250 & 1100 \\
\hline
\end{tabular}

\subsection{Obtaining a first feasible basic solution}

We have: $\sum_{i=1}^{3} a_{i}=350+350+400=1100$ and $\sum_{j=1}^{4} b_{j}=300+300+250+250=1100$, so $\sum_{i=1}^{3} a_{i}=\sum_{j=1}^{4} b_{j}$. We are therefore faced with a problem of balanced transport. 
Since Vogel's Approximation method, as we had seen previously generally generates optimal solutions, we will deploy the first two heuristics stated above, in order to generate a feasible basic solution, and we will do in another section, the optimality test.

\subsubsection{The North-West Corner method}

\section{Iteration 1}

\section{Step 1}

The table modeling the transport problem consists of three rows and four columns; its North-West Corner is cell $(1 ; 1)$, so $x_{11}$ goes into the base.

\section{Step 2}

$x_{11}=\min \left\{a_{1} ; b_{1}\right\}=\min \{350 ; 300\}=300$

$a_{1}^{\prime}=a_{1}-x_{11}=350-300=50$

$b_{1}^{\prime}=b_{1}-x_{11}=300-300=0$

\section{Step 3}

$a_{1}^{\prime}=50$ and $b_{1}^{\prime}=0$, we eliminate column 1 .

\section{Step 4}

We have three rows and three columns left, so we're not done (see Table 3).

Table 3 Result obtained after the first iteration of the North-West Corner method

\begin{tabular}{|c|c|c|c|c|c|}
\hline Origin Destination & $\mathbf{1}$ & $\mathbf{2}$ & $\mathbf{3}$ & $\mathbf{4}$ & Supply \\
\hline 1 & $\begin{array}{c}25 \\
\mathbf{3 0 0}\end{array}$ & 18 & 17 & 15 & 350 \\
& 24 & 19 & 13 & 11 & 350 \\
\hline 2 & 22 & 14 & 12 & 10 & 400 \\
\hline 3 & 300 & 300 & 250 & 250 & 1100 \\
\hline Demand & 0 & & & & \\
\hline
\end{tabular}

\section{Iteration 2}

\section{Step 1}

The remaining table consists of rows 1, 2 and 3, and columns 2, 3 and 4; its North-West Corner is cell $(1 ; 2)$, so $x_{12}$ enters the base.

Step 2

$x_{12}=\min \left\{a_{1} ; \mathrm{b}_{2}\right\}=\min \{50 ; 300\}=50$

$a_{1}^{\prime}=a_{1}-x_{12}=50-50=0$

$b_{2}^{\prime}=b_{2}-x_{12}=300-50=250$

\section{Step 3}

$a_{1}^{\prime}=0$ and $b_{2}^{\prime}=250$, we eliminate ligne (row) 1 . 


\section{Step 4}

We have two rows and three columns left, so we have to repeat the process from step 1 in order to operate a third iteration (see Table 4).

Table 4 Result obtained after the second iteration of the North-West Corner method

\begin{tabular}{|c|c|c|c|c|c|}
\hline Origin Destination & $\mathbf{1}$ & $\mathbf{2}$ & $\mathbf{3}$ & $\mathbf{4}$ & Supply \\
\hline 1 & 25 & 18 & 17 & 15 & 350 \\
& $\mathbf{3 0 0}$ & $\mathbf{5 0}$ & & & 0 \\
\hline 2 & 24 & 19 & 13 & 11 & 350 \\
\hline 3 & 22 & 14 & 12 & 10 & 400 \\
\hline Demand & $\begin{array}{c}300 \\
0\end{array}$ & $\begin{array}{c}300 \\
250\end{array}$ & 250 & 250 & 1100 \\
\hline
\end{tabular}

\section{Iteration 3}

\section{Step 1}

There are rows 2 and 3 and columns 2, 3 and 4 left, so the North-West Corner is cell $(2 ; 2)$, so $x_{22}$ enters the base.

\section{Step 2}

$x_{22}=\min \left\{a_{2} ; \mathrm{b}_{2}\right\}=\min \{350 ; 250\}=250$

$a_{2}^{\prime}=a_{2}-x_{22}=350-250=100$

$b_{2}^{\prime}=b_{2}-x_{22}=250-250=0$

\section{Step 3}

$a_{2}^{\prime}=100$ and $b_{2}^{\prime}=0$, we eliminate column 2 .

\section{Step 4}

Since there are two rows and two columns remaining, a fourth iteration is necessary (see Table 5).

Table 5 Result obtained after the third iteration of the North-West Corner method

\begin{tabular}{|c|c|c|c|c|c|}
\hline Origin Destination & $\mathbf{1}$ & $\mathbf{2}$ & $\mathbf{3}$ & $\mathbf{4}$ & Supply \\
\hline 4 & 25 & 18 & 17 & 15 & 350 \\
& $\mathbf{3 0 0}$ & $\mathbf{5 0}$ & & & 0 \\
\hline 2 & 24 & $\begin{array}{c}19 \\
\mathbf{2 5 0}\end{array}$ & 13 & 11 & 350 \\
& & $\mathbf{2 5 0}$ & & 100 \\
\hline 3 & 22 & 14 & 12 & 10 & 400 \\
\hline Demand & 300 & 300 & 250 & 250 & 1100 \\
& 0 & 0 & & & \\
\hline
\end{tabular}

\section{Iteration 4}

\section{Step 1}

Row 2 and 3 and columns 3 and 4 remain, so the North-West Corner is cell $(2 ; 3)$, so $x_{23}$ enters the base.

\section{Step 2}

$x_{23}=\min \left\{a_{2} ; \mathrm{b}_{3}\right\}=\min \{100 ; 250\}=100$ 
$a_{2}^{\prime}=a_{2}-x_{23}=100-100=0$

$b_{3}^{\prime}=b_{3}-x_{23}=250-100=150$

\section{Step 3}

$a_{2}^{\prime}=0$ and $b_{3}^{\prime}=150$, we eliminate ligne 2 .

\section{Step 4}

Since there is one row and two columns remaining, a fifth iteration is necessary (see Table 6).

Table 6 Result obtained after the fourth iteration of the North-West Corner method

\begin{tabular}{|c|c|c|c|c|c|}
\hline Origin Destination & $\mathbf{1}$ & $\mathbf{z}$ & $\mathbf{3}$ & $\mathbf{4}$ & Supply \\
\hline 4 & 25 & 18 & 17 & 15 & 350 \\
& 300 & 50 & & & 0 \\
\hline$z$ & 24 & $\begin{array}{c}19 \\
\mathbf{2 5 0}\end{array}$ & $\begin{array}{c}13 \\
\mathbf{1 0 0}\end{array}$ & 11 & 350 \\
& & $\mathbf{2 0}$ & 0 \\
\hline 3 & $z 2$ & 14 & 12 & 10 & 400 \\
\hline Demand & 300 & 300 & 250 & 250 & 1100 \\
& 0 & 0 & 150 & & \\
\hline
\end{tabular}

\section{Iteration 5}

\section{Step 1}

Row 3 and columns 3 and 4 remain, so the North-West Corner is cell $(3 ; 3)$, so $x_{33}$ goes into the base.

\section{Step 2}

$x_{33}=\min \left\{a_{3} ; \mathrm{b}_{3}\right\}=\min \{400 ; 150\}=150$

$a_{3}^{\prime}=a_{3}-x_{33}=400-150=250$

$b_{3}^{\prime}=b_{3}-x_{33}=150-150=0$

\section{Step 3}

$a_{3}^{\prime}=250$ and $b_{3}^{\prime}=0$, so we eliminate column 3 .

\section{Step 4}

Since there is one row and one column left, a sixth iteration is necessary (see Table 7).

Table 7 Result obtained after the fifth iteration of the North-West Corner method

\begin{tabular}{|c|c|c|c|c|c|}
\hline Origin Destination & $\mathbf{1}$ & $\mathbf{2}$ & $\mathbf{3}$ & $\mathbf{4}$ & Supply \\
\hline 1 & $\mathbf{2 5}$ & $\mathbf{1 8}$ & 17 & 15 & 350 \\
& $\mathbf{3 0 0}$ & $\mathbf{5 0}$ & & & 0 \\
\hline 2 & 24 & 19 & 13 & 11 & 350 \\
& & $\mathbf{2 5 0}$ & $\mathbf{1 0 0}$ & & 0 \\
\hline 3 & 22 & 14 & 12 & 10 & 400 \\
& & & 150 & & 250 \\
\hline Demand & 300 & 300 & 250 & 250 & 1100 \\
& 0 & 0 & 0 & & \\
\hline
\end{tabular}




\section{Iteration 6}

\section{Step 1}

Row 3 and column 4 remain, so the North-West Corner is cell $(3 ; 4)$, so $x_{34}$ goes into the base.

\section{Step 2}

$x_{34}=\min \left\{a_{3} ; \mathrm{b}_{4}\right\}=\min \{250 ; 250\}=250$

$a_{3}^{\prime}=a_{3}-x_{34}=150-150=0$

$b_{4}^{\prime}=b_{4}-x_{34}=150-150=0$

\section{Step 3}

$a_{3}^{\prime}=250$ and $b_{4}^{\prime}=0$, so we eliminate column 4 .

\section{Step 4}

Only row 3 remains, the initial basic workable solution is found (see Table 8).

Table 8 Result obtained after the sixth iteration of the North-West Corner method

\begin{tabular}{|c|c|c|c|c|c|}
\hline Origin Destination & $\mathbf{1}$ & $\mathbf{2}$ & $\mathbf{3}$ & $\mathbf{4}$ & Supply \\
\hline 1 & 25 & 18 & 17 & 15 & 350 \\
& $\mathbf{3 0 0}$ & $\mathbf{5 0}$ & & & 0 \\
\hline 2 & 24 & 19 & 13 & 11 & 350 \\
& & $\mathbf{2 5 0}$ & $\mathbf{1 0 0}$ & & 0 \\
\hline 3 & 22 & 14 & 12 & 10 & 400 \\
& & & $\mathbf{1 5 0}$ & $\mathbf{2 5 0}$ & 0 \\
\hline Demand & 300 & 300 & 250 & 250 & 1100 \\
& 0 & 0 & 0 & 0 & \\
\hline
\end{tabular}

We can calculate the total cost of transporting the basic non-degenerate solution, deduced from the North-West Corner method as follows:

$$
\begin{aligned}
& \mathrm{z}=c_{11} x_{11}+c_{12} x_{12}+c_{22} x_{22}+c_{23} x_{23}+c_{33} x_{33}+c_{34} x_{34} \\
& =25(300)+18(50)+19(250)+13(100)+12(150)+10(250) \\
& =18750
\end{aligned}
$$

\subsubsection{The Minimum Cost method}

Let us apply the minimal matrix method to the problem in Table 2.

\section{Iteration 1}

\section{Step 1}

The cell $(p ; q)$ chosen is the cell $(3 ; 4)$ whose cost $(10)$ is the smallest in the entire table.

\section{Step 2}

Calculate $x_{34}, a_{3}^{\prime}$ and $b_{4}^{\prime}$

$x_{34}=\min \left\{a_{3} ; \mathrm{b}_{4}\right\}=\min \{400 ; 250\}=250$ 
$a_{3}^{\prime}=a_{3}-x_{34}=400-250=150$

$b_{4}^{\prime}=b_{4}-x_{34}=250-250=0$

\section{Step 3}

Like $a_{3}^{\prime}=150$ and $b_{4}^{\prime}=0$, we therefore eliminate column 4 .

\section{Step 4}

There are three rows $(1,2$ and 3$)$ and three columns (1,2 and 3) left, so you have to choose a new $x_{p q}$ which will in turn enter the initial basic feasible solution. Table 9 is obtained after the first iteration.

Table 9 Result obtained after the first iteration of the Minimum Cost method

\begin{tabular}{|c|c|c|c|c|c|}
\hline Origin Destination & $\mathbf{1}$ & $\mathbf{2}$ & $\mathbf{3}$ & $\mathbf{4}$ & Supply \\
\hline 1 & 25 & 18 & 17 & 15 & 350 \\
\hline 2 & 24 & 19 & 13 & 11 & 350 \\
\hline 3 & 22 & 14 & 12 & $\begin{array}{c}10 \\
\mathbf{2 5 0}\end{array}$ & $\begin{array}{c}400 \\
150\end{array}$ \\
\hline Demand & 300 & 300 & 250 & $\begin{array}{c}250 \\
0\end{array}$ & 1100 \\
\hline
\end{tabular}

\section{Iteration 2}

\section{Step 1}

The minimum cost in Table 9 is that of cell $(3 ; 3)$; we will therefore introduce $x_{33}$.

\section{Step 2}

$x_{33}=\min \left\{a_{3} ; b_{3}\right\}=\min \{150 ; 250\}=150$

$a_{3}^{\prime}=a_{3}-x_{33}=150-150=0$

$b_{3}^{\prime}=b_{3}-x_{33}=250-150=100$

\section{Step 3}

$a_{3}^{\prime}=0$ and $b_{3}^{\prime}=100$, so we must eliminate row 3 .

\section{Step 4}

Table 10 Result obtained after the second iteration of the Minimum Cost method

\begin{tabular}{|c|c|c|c|c|c|}
\hline Origin $\quad$ Destination & 1 & 2 & 3 & 4 & Supply \\
\hline 1 & 25 & 18 & 17 & 15 & 350 \\
\hline 2 & 24 & 19 & 13 & 11 & 350 \\
\hline 3 & 22 & 14 & $\begin{array}{c}12 \\
\mathbf{1 5 0}\end{array}$ & $\begin{array}{c}10 \\
250\end{array}$ & $\begin{array}{c}400 \\
0\end{array}$ \\
\hline Demand & 300 & 300 & $\begin{array}{l}250 \\
100\end{array}$ & $\begin{array}{c}250 \\
0\end{array}$ & 1100 \\
\hline
\end{tabular}


Since there are two rows and three columns left, we are not finished, so we are looking for the third $x_{p q}$ which will in turn enter the initial basic workable solution.

Table 10 is obtained after the second iteration.

\section{Iteration 3}

\section{Step 1}

The minimum cost on rows 1 and 2 , and columns 1,2 and 3 is 13 , which is the cost of cell $(2 ; 3)$.

\section{Step 2}

$x_{23}=\min \left\{a_{2} ; \mathrm{b}_{3}\right\}=\min \{350 ; 100\}=100$

$a_{2}^{\prime}=a_{2}-x_{23}=350-100=250$

$b_{3}^{\prime}=b_{3}-x_{23}=100-100=0$

\section{Step 3}

$a_{2}^{\prime}=250$ and $b_{3}^{\prime}=0$, so column 3 must be eliminated.

\section{Step 4}

There are two rows and two columns left, so we need to do a fourth iteration.

Table 11 is obtained after the third iteration.

Table 11 Result obtained after the third iteration of the Minimum Cost method

\begin{tabular}{|c|c|c|c|c|c|}
\hline Origin Destination & $\mathbf{1}$ & $\mathbf{2}$ & $\mathbf{3}$ & $\mathbf{4}$ & Supply \\
\hline 1 & 25 & 18 & 17 & 15 & 350 \\
\hline 2 & 24 & 19 & $\begin{array}{c}13 \\
\mathbf{1 0 0}\end{array}$ & $\begin{array}{l}11 \\
350 \\
250\end{array}$ \\
\hline 3 & 22 & 14 & $\begin{array}{c}12 \\
\mathbf{1 5 0}\end{array}$ & $\begin{array}{c}\mathbf{2 5 0} \\
400\end{array}$ \\
\hline Demand & 300 & 300 & $\begin{array}{c}250 \\
0\end{array}$ & $\begin{array}{c}250 \\
0\end{array}$ & \begin{tabular}{c}
1100 \\
\hline
\end{tabular} \\
\hline
\end{tabular}

\section{Iteration 4}

\section{Step 1}

The minimum cost on rows 1 and 2 , and columns 1 and 2 is 18 , which is the cost of cell $(1 ; 2)$.

\section{Step 2}

$x_{12}=\min \left\{a_{1} ; \mathrm{b}_{2}\right\}=\min \{350 ; 300\}=300$

$a_{1}^{\prime}=a_{1}-x_{12}=350-300=50$

$b_{2}^{\prime}=b_{2}-x_{12}=300-300=0$

\section{Step 3}

$a_{1}^{\prime}=50$ and $b_{2}^{\prime}=0$, so column 2 must be eliminated. 


\section{Step 4}

There are two rows and one column left, so we need to do a fifth iteration. Table 12 is obtained after the fourth iteration.

Table 12 Result obtained after the fourth iteration of the Minimum Cost method

\begin{tabular}{|c|c|c|c|c|c|}
\hline Origin Destination & $\mathbf{1}$ & $\mathbf{2}$ & $\mathbf{3}$ & $\mathbf{4}$ & Supply \\
\hline 1 & 25 & $\begin{array}{c}18 \\
\mathbf{3 0 0}\end{array}$ & $\begin{array}{l}17 \\
15\end{array}$ & $\begin{array}{c}350 \\
50\end{array}$ \\
\hline 2 & 24 & 19 & 13 & 11 & 350 \\
& & & $\mathbf{1 0 0}$ & & 250 \\
\hline 3 & 22 & 14 & 12 & 10 & 400 \\
& & & $\mathbf{1 5 0}$ & $\mathbf{2 5 0}$ & 0 \\
\hline Demand & 300 & 300 & $\begin{array}{c}250 \\
0\end{array}$ & $\begin{array}{c}250 \\
0\end{array}$ & $\begin{array}{c}1100 \\
0\end{array}$ \\
\hline
\end{tabular}

\section{Iteration 5}

\section{Step 1}

The minimum cost of Table 12 remaining is 24 , which is the cost of the cell $(2 ; 1)$.

\section{Step 2}

$x_{21}=\min \left\{a_{2} ; \mathrm{b}_{1}\right\}=\min \{250 ; 300\}=250$

$a_{2}^{\prime}=a_{2}-x_{21}=250-250=0$

$b_{1}^{\prime}=b_{1}-x_{21}=300-250=50$

\section{Step 3}

$a_{2}^{\prime}=0$ and $b_{1}^{\prime}=50$, so we have to eliminate row 2 .

\section{Step 4}

There is one row and one column left, so we need to do a sixth iteration. Table 13 is obtained after the fifth iteration.

Table 13 Result obtained after the fifth iteration of the Minimum Cost method

\begin{tabular}{|c|c|c|c|c|c|}
\hline Origin Destination & $\mathbf{1}$ & $\mathbf{2}$ & $\mathbf{3}$ & $\mathbf{4}$ & Supply \\
\hline 1 & 25 & $\begin{array}{c}18 \\
\mathbf{3 0 0}\end{array}$ & $\begin{array}{l}17 \\
15\end{array}$ & $\begin{array}{c}350 \\
50\end{array}$ \\
\hline 2 & 24 & 19 & 13 & 11 & 350 \\
& $\mathbf{2 5 0}$ & & $\mathbf{1 0 0}$ & & 0 \\
\hline 3 & 22 & 14 & 12 & 10 & 400 \\
& & & $\mathbf{1 5 0}$ & $\mathbf{2 5 0}$ & 0 \\
\hline Demand & 300 & 300 & 250 & 250 & 1100 \\
& 50 & 0 & 0 & 0 & \\
\hline
\end{tabular}

\section{Iteration 6}

\section{Step 1}

The only $x_{p q}$ that can still enter the base is $x_{11}$. 


\section{Step 2}

$x_{11}=\min \left\{a_{1} ; \mathrm{b}_{1}\right\}=\min \{50 ; 50\}=50$

$a_{1}^{\prime}=a_{1}-x_{11}=50-50=0$

$b_{1}^{\prime}=b_{1}-x_{11}=50-50=0$

\section{Step 3}

$a_{1}^{\prime}=0$ and $b_{1}^{\prime}=0$, row 1 is the last of the rows, so we eliminate column 1 .

\section{Step 4}

Only row 1 remains, so we're done.

The basic feasible solution is given in Table 14 .

Table 14 Result obtained after the sixth iteration of the Minimum Cost method

\begin{tabular}{|c|c|c|c|c|c|}
\hline Origin Destination & $\mathbf{1}$ & $\mathbf{2}$ & $\mathbf{3}$ & $\mathbf{4}$ & Supply \\
\hline 1 & 25 & 18 & 17 & 15 & 350 \\
& $\mathbf{5 0}$ & $\mathbf{3 0 0}$ & & & 0 \\
\hline$z$ & 24 & 19 & 13 & 11 & 350 \\
& $\mathbf{2 5 0}$ & & $\mathbf{1 0 0}$ & & 0 \\
\hline 3 & 22 & 14 & 12 & 10 & 400 \\
& & & $\mathbf{1 5 0}$ & $\mathbf{2 5 0}$ & 0 \\
\hline Demand & 300 & 300 & 250 & 250 & 1100 \\
& 0 & 0 & 0 & 0 & \\
\hline
\end{tabular}

The total cost of transport generated by this method is evaluated as follows:

$$
\begin{aligned}
& \mathrm{Z}=c_{11} x_{11}+c_{12} x_{12}+c_{21} x_{21}+c_{23} x_{23}+c_{33} x_{33}+c_{34} x_{34} \\
& =25(50)+18(300)+24(250)+13(100)+12(150)+10(250) \\
& =18250
\end{aligned}
$$

The Minimum Cost method generates a better base solution than that obtained with the Northwest Corner Method, with a lower overall transport cost.

\subsection{Testing the initial base solution for optimality}

We apply the Modified Distribution method to test the optimality of the base solutions previously generated, respectively by the Northwest Corner method and the Minimum Cost method.

\subsubsection{Optimality test of the basic solution generated by the Northwest Corner method}

\section{Iteration 1}

\section{Step 1}

Calculate $u_{i}$ and $v_{j}$ for all allocated cells, by the relation $u_{i}+v_{j}=c_{i j}$, where $c_{i j}$ is the unit transport cost for cell $(i ; j)$

From the basic solution generated by the Northwest Corner method, we have the following reduced equations: 
$\left\{\begin{array}{l}x_{11}: u_{1}+v_{1}=25 \\ x_{12}: u_{1}+v_{2}=18 \\ x_{22}: u_{2}+v_{2}=19\end{array} ; \quad\left\{\begin{array}{l}x_{23}: u_{2}+v_{3}=13 \\ x_{33}: u_{3}+v_{3}=12 \\ x_{34}: u_{3}+v_{4}=10\end{array}\right.\right.$

\section{Step 2}

We set $u_{1}=0$ and we get:

$v_{1}=25 ; v_{2}=18 ; u_{2}=1 ; v_{3}=12 ; u_{3}=0$ and $v_{4}=10$.

\section{Step 3}

Evaluate all blank cells by formula $\Delta_{i j}=c_{i j}-u_{i}-v_{j}$ :

$\left\{\begin{array}{l}x_{13}: \Delta_{13}=c_{13}-u_{1}-v_{3}=17-0-12=5 \\ x_{14}: \Delta_{14}=c_{14}-u_{1}-v_{4}=15-0-10=5 \\ x_{21}: \Delta_{21}=c_{21}-u_{2}-v_{1}=24-1-25=-2\end{array} ;\left\{\begin{array}{l}x_{24}: \Delta_{24}=c_{24}-u_{2}-v_{4}=11-1-10=0 \\ x_{31}: \Delta_{31}=c_{31}-u_{3}-v_{1}=22-0-25=-3 \\ x_{32}: \Delta_{32}=c_{32}-u_{3}-v_{2}=14-0-18=-4\end{array}\right.\right.$

Not all $\Delta_{i j}$ 's are positive, so the resulting base solution is not optimal.

\section{Step 4}

We see that the cell $(3 ; 2)$ has the most negative improvement index, so the maximum amount of material to be introduced into this cell is:

$x_{32}^{\prime}=\min \left\{x_{22} ; x_{33}\right\}=\min \{250 ; 150\}=150$

It follows that:

$x_{23}^{\prime}=x_{23}+x_{32}^{\prime}=100+150=250$

$x_{22}^{\prime}=x_{22}-x_{32}^{\prime}=250-150=100$

$x_{33}^{\prime}=x_{33}-x_{32}^{\prime}=150-150=0$

Cell $(3 ; 2)$ enters the base, but cell $(3 ; 3)$ exits.

After change of base, we obtain Table 15.

Table 15 First change of the basic solution obtained by the North-West Corner method

\begin{tabular}{|c|c|c|c|c|c|}
\hline Origin $\quad$ Destination & 1 & 2 & 3 & 4 & Supply \\
\hline 1 & $\begin{array}{c}25 \\
\mathbf{3 0 0}\end{array}$ & $\begin{array}{l}18 \\
\mathbf{5 0}\end{array}$ & 17 & 15 & 350 \\
\hline 2 & 24 & $\begin{array}{c}19 \\
100\end{array}$ & $\begin{array}{c}13 \\
250\end{array}$ & 11 & 350 \\
\hline 3 & 22 & $\begin{array}{c}14 \\
\mathbf{1 5 0}\end{array}$ & 12 & $\begin{array}{c}10 \\
\mathbf{2 5 0}\end{array}$ & 400 \\
\hline Demand & 300 & 300 & 250 & 250 & 1100 \\
\hline
\end{tabular}




\section{Iteration 2}

\section{Step 1}

$\left\{\begin{array}{l}x_{11}: u_{1}+v_{1}=25 \\ x_{12}: u_{1}+v_{2}=18 \\ x_{22}: u_{2}+v_{2}=19\end{array} ;\left\{\begin{array}{l}x_{23}: u_{2}+v_{3}=13 \\ x_{32}: u_{3}+v_{2}=14 \\ x_{34}: u_{3}+v_{4}=10\end{array}\right.\right.$

\section{Step 2}

We set $u_{1}=0$ and we get:

$v_{1}=25 ; v_{2}=18 ; u_{2}=1 ; v_{3}=12 ; u_{3}=-4$ and $v_{4}=14$.

\section{Step 3}

$\left\{\begin{array}{l}x_{13}: \Delta_{13}=c_{13}-u_{1}-v_{3}=17-0-12=5 \\ x_{14}: \Delta_{14}=c_{14}-u_{1}-v_{4}=15-0-14=1 \\ x_{21}: \Delta_{21}=c_{21}-u_{2}-v_{1}=24-1-25=-2\end{array} ; \quad\left\{\begin{array}{l}x_{24}: \Delta_{24}=c_{24}-u_{2}-v_{4}=11-1-14=-4 \\ x_{31}: \Delta_{31}=c_{31}-u_{3}-v_{1}=22-(-4)-25=1 \\ x_{33}: \Delta_{33}=c_{33}-u_{3}-v_{3}=12-(-4)-12=4\end{array}\right.\right.$

\section{Step 4}

Cell $(2 ; 4)$ has the most negative improvement index, so the maximum amount of material to be introduced into this cell is:

$x_{24}^{\prime}=\min \left\{x_{22} ; x_{34}\right\}=\min \{100 ; 250\}=100$

It follows that:

$x_{32}^{\prime}=x_{32}+x_{24}^{\prime}=150+250=400$

$x_{22}^{\prime}=x_{22}-x_{24}^{\prime}=100-100=0$

$x_{34}^{\prime}=x_{34}-x_{24}^{\prime}=250-100=150$

Cell $(2 ; 2)$ comes out of the base, but cell $(2 ; 4)$ enters.

After changing the base, we obtain Table 16.

Table 16 Second change of the basic solution obtained by the North-West Corner method

\begin{tabular}{|c|c|c|c|c|c|}
\hline Origin Destination & $\mathbf{1}$ & $\mathbf{2}$ & $\mathbf{3}$ & $\mathbf{4}$ & Supply \\
\hline 1 & 25 & 18 & 17 & 15 & 350 \\
& $\mathbf{3 0 0}$ & $\mathbf{5 0}$ & & & \\
\hline 2 & 24 & 19 & $\begin{array}{c}13 \\
\mathbf{2 5 0}\end{array}$ & $\mathbf{1 0 0}$ & 350 \\
\hline 3 & 22 & $\begin{array}{c}14 \\
\mathbf{4 0 0}\end{array}$ & 12 & $\begin{array}{c}10 \\
\mathbf{1 5 0}\end{array}$ & 400 \\
\hline Demand & 300 & 300 & 250 & 250 & 1100 \\
\hline
\end{tabular}




\section{Iteration 3}

\section{Step 1}

$\left\{\begin{array}{l}x_{11}: u_{1}+v_{1}=25 \\ x_{12}: u_{1}+v_{2}=18 \\ x_{23}: u_{2}+v_{3}=13\end{array} ;\left\{\begin{array}{l}x_{24}: u_{2}+v_{4}=11 \\ x_{32}: u_{3}+v_{2}=14 \\ x_{34}: u_{3}+v_{4}=10\end{array}\right.\right.$

\section{Step 2}

We set $u_{1}=0$ and we get:

$v_{1}=25 ; v_{2}=18 ; u_{3}=-4 ; u_{2}=-3 ; v_{3}=16$ and $v_{4}=14$.

\section{Step 3}

$\left\{\begin{array}{l}x_{13}: \Delta_{13}=c_{13}-u_{1}-v_{3}=17-0-16=1 \\ x_{14}: \Delta_{14}=c_{14}-u_{1}-v_{4}=15-0-14=1 \\ x_{21}: \Delta_{21}=c_{21}-u_{2}-v_{1}=24-(-3)-25=2\end{array} ; \quad\left\{\begin{array}{l}x_{22}: \Delta_{22}=c_{22}-u_{2}-v_{2}=19-(-3)-18=4 \\ x_{31}: \Delta_{31}=c_{31}-u_{3}-v_{1}=22-(-4)-25=1 \\ x_{33}: \Delta_{33}=c_{33}-u_{3}-v_{3}=12-(-4)-16=0\end{array}\right.\right.$

All the $\Delta_{i j}$ values are positive or zero, so the solution obtained is optimal.

$\mathrm{z}=c_{11} x_{11}+c_{12} x_{12}+c_{23} x_{23}+c_{24} x_{24}+c_{32} x_{32}+c_{34} x_{34}$

$=17850$

\subsubsection{Optimality test of the base solution generated by the Minimum Cost method}

\section{Iteration 1}

\section{Step 1}

From the basic solution generated by the Minimum Cost method, we have the following reduced equations:

$\left\{\begin{array}{l}x_{11}: u_{1}+v_{1}=25 \\ x_{12}: u_{1}+v_{2}=18 \\ x_{21}: u_{2}+v_{1}=24\end{array} ; \quad\left\{\begin{array}{l}x_{23}: u_{2}+v_{3}=13 \\ x_{33}: u_{3}+v_{3}=12 \\ x_{34}: u_{3}+v_{4}=10\end{array}\right.\right.$

\section{Step 2}

We set $u_{1}=0$ and we get :

$v_{1}=25 ; v_{2}=18 ; u_{2}=-1 ; v_{3}=14 ; u_{3}=-2$ and $v_{4}=12$.

\section{Step 3}

$\left\{\begin{array}{l}x_{13}: \Delta_{13}=c_{13}-u_{1}-v_{3}=17-0-14=3 \\ x_{14}: \Delta_{14}=c_{14}-u_{1}-v_{4}=15-0-12=3 \\ x_{22}: \Delta_{22}=c_{22}-u_{2}-v_{2}=19-(-1)-18\end{array} ; \quad ; \quad\left\{\begin{array}{l}x_{24}: \Delta_{24}=c_{24}-u_{2}-v_{4}=11-(-1)-12=0 \\ x_{31}: \Delta_{31}=c_{31}-u_{3}-v_{1}=22-(-2)-25=-1 \\ x_{32}: \Delta_{32}=c_{32}-u_{3}-v_{2}=14-(-2)-18=-2\end{array}\right.\right.$

\section{Step 4}

We see that cell $(3 ; 2)$ has the most negative improvement index, so the maximum amount of material to be introduced into this cell is: 
$x_{32}^{\prime}=\min \left\{x_{21} ; x_{12}\right\}=\min \{250 ; 300\}=250$

It follows that:

$x_{11}^{\prime}=x_{11}+x_{32}^{\prime}=50+250=300$

$x_{21}^{\prime}=x_{21}-x_{32}^{\prime}=250-250=0$

$x_{12}^{\prime}=x_{12}-x_{32}^{\prime}=300-250=50$

Cell $(3 ; 2)$ enters the base, but cell $(2 ; 1)$ exits.

After changing the base, we obtain Table 17.

Table 17 Change of the basic solution obtained by the Minimum Cost method

\begin{tabular}{|c|c|c|c|c|c|}
\hline Origin Destination & 1 & 2 & 3 & 4 & Supply \\
\hline 1 & $\begin{array}{c}25 \\
\mathbf{3 0 0}\end{array}$ & $\begin{array}{l}18 \\
\mathbf{5 0}\end{array}$ & 17 & 15 & 350 \\
\hline 2 & 24 & 19 & $\begin{array}{c}13 \\
100\end{array}$ & 11 & 350 \\
\hline 3 & 22 & $\begin{array}{c}14 \\
250\end{array}$ & $\begin{array}{c}12 \\
\mathbf{1 5 0}\end{array}$ & $\begin{array}{c}10 \\
250\end{array}$ & 400 \\
\hline Demand & 300 & 300 & 250 & 250 & 1100 \\
\hline
\end{tabular}

\section{Iteration 2}

\section{Step 1}

$\left\{\begin{array}{l}x_{11}: u_{1}+v_{1}=25 \\ x_{12}: u_{1}+v_{2}=18 \\ x_{23}: u_{2}+v_{3}=13\end{array} ; \quad\left\{\begin{array}{l}x_{32}: u_{3}+v_{2}=14 \\ x_{33}: u_{3}+v_{3}=12 \\ x_{34}: u_{3}+v_{4}=10\end{array}\right.\right.$

\section{Step 2}

We set $u_{1}=0$ and we get:

$v_{1}=25 ; v_{2}=18 ; u_{3}=-4 ; v_{3}=16 ; u_{2}=-3$ and $v_{4}=14$.

\section{Step 3}

$\left\{\begin{array}{l}x_{13}: \Delta_{13}=c_{13}-u_{1}-v_{3}=17-0-16=1 \\ x_{14}: \Delta_{14}=c_{14}-u_{1}-v_{4}=15-0-14=1 \\ x_{21}: \Delta_{21}=c_{21}-u_{2}-v_{1}=24-(-3)-25=2\end{array} ; \quad\left\{\begin{array}{l}x_{22}: \Delta_{22}=c_{22}-u_{2}-v_{2}=19-(-3)-18=4 \\ x_{24}: \Delta_{24}=c_{24}-u_{2}-v_{4}=11-(-3)-14=0 \\ x_{31}: \Delta_{31}=c_{31}-u_{3}-v_{1}=22-(-4)-25=1\end{array}\right.\right.$

All the $\Delta_{i j}$ values are positive or zero, so the solution obtained is optimal.

$\mathrm{z}=c_{11} x_{11}+c_{12} x_{12}+c_{23} x_{23}+c_{32} x_{32}+c_{33} x_{33}+c_{34} x_{34}$

$=17500$ 
We see that after the application of the optimality test in the search for the optimal solution, the Minimum Cost Method is the one that generates the most optimum cost (The lowest cost). It is therefore this method that leads to obtaining the optimal transport network.

The optimal transport network is given by Figure 4



Figure 4 The optimal transport network

\section{Conclusion}

At the end of the drafting of this paper, we have deployed a heuristic approach to optimize the transport problem mechanical parts of a production plant. Starting from the graphical modeling of this transport problem, we first deduced the matrix formulation. Then, we embarked on the search for the basic solution by two heuristics: the Northwest Corner method and the Minimum Cost method, and we obtained feasible basic solutions. Finally, by an optimality test, the Modified Distribution method showed that the base solutions obtained previously are not optimal. In improving these solutions, one obtains a better optimal solution, when one improves the base solution generated by the Minimum Cost method.

\section{Compliance with ethical standards}

\section{Acknowledgments}

The authors would like to thank the anonymous reviewers for their time and effort. Their constructive comments and helpful suggestions helped us to clarify the main paper's research contributions and improve its quality.

\section{Disclosure of conflict of interest}

The authors declare no conflicts of interest regarding the publication of this paper.

\section{References}

[1] Hitchcock FL. The distribution of a product from several sources to numerous locdities. Journal Math. Phys. 1941; 20: $224-230$.

[2] Koopmans TC. Optimum Utilization of the Transportation systems. Econometrica. 1949; 17: $136-146$.

[3] Kantorovich LV. On the translocations of masses. Management Science. 1958 ;5 (1) .1-4.

[4] Ndayiragije F. Transportation Problem: South-East Corner Method and a Comparative Study on the North-West Corner, South-East Corner, North-East Corner and South-West Corner Methods. International Journal of Science and Engineering Investigations. 2017; 6 (64): 37-39. 
[5] Dantzig GB. Linear Programming and Extensions. Princeton University Press. 1963.

[6] Palaniyappa R, Vinoba V. A study of balanced transportation problem and use of object oriented programming. International Research Journal of pure Algebra. 2014; 4 (4): 25274-25275.

[7] Pallavi P L, Lakshmi R A. A Mat Lab Oriented Approch to Solve the Transportation Problem. International Journal of Advanced Research Foundation. 2015a; 2 (11): 1-4.

[8] Lakshmi RA, Pallavi P L. A New Approach to Study Transportation Problem Using South West Corner Rule. International Journal of Advanced Research Foundation. 2015 b; 2 (12) :1-3.

[9] Jaehyung A, Alexey M, Sang-UK J. A linear Programming approach for robust network revenue management in the airline industry. Journal of Air Transport Management. 2021; 91: 101979: 1-7.

[10] Adlakha V, Kowalski K, Lev B. Solving transportation problems with mixed constraints. International Journal of Management Science and Engineering Management. 2006; 1(1) :47-52.

[11] Pandian P, Natarajan G. A New Approach for solving Transportation Problems with Mixed Constraints. Journal of Physical Sciences. 2010; 14: 53 -61.

[12] Anderson D R, Sweeney D J, Williams T A, Camm JD, Martin K. An Introduction to Management Science Quantitative Approaches to Decision Making. South-Western CENGAGE Learning UK, United Kingdom, Student Edition. 2012; 13: 978-1-111-53224-6.

[13] Lev B. A non-iterative algorithm for tridiagonal transportation problems and its generalization. Journal of Operations Research Society of America. 1972; 20: 109-125.

[14] Lev B, Intrator Y. Applications of vanishing variables methods to special structured transportation problems. Computers and Operations Research. 1977; 4: 21-26.

[15] Arsham H. Postoptimality analyses of the transportation problem. Journal of the Operational Research Society. 1992; 43: 121-139.

[16] Adlakha V, Kowalski K. A heuristic method for more-for-less in distribution related problems. International Journal of Mathematical Education in Science and Technology. 2001; 32: 61-71.

[17] Adlakha V, Kowalski K, Lev B, Vemuganti R R. More-for-less algorithm for fixed -charge transportation problems. The International Journal of Management Science. 2007; 35 (1): 1-20.

[18] Adlakha V, Kowalski K, Lev B. A branching method for the fixed charge transportation problem. Omega. $2010 ; 38$ (5): 393-397.

[19] Rekha V J. Optimization Techniques for Transportation Problems of Three Variables. IOSR Journal of Mathematics (IOSR-JM), e-ISSN: 2278-5728, p-ISSN :2319-765X. 2013; 9 (1) :46-50.

[20] Abdul S S, Muhammad J, Gurudeo A T. Modified Vogel's Approximation Method For Solving Transportation Problems. Mathematical Theory and Modeling. 2015; 5 (42225-0522): 32-42.

[21] Kavitha M, Vinoba V. A Study on Transportation problem using stepping stone method and its Applications. International Journal of Mathematics Trends and Technology. 2015; 22 (1) :52-54.

[22] Dodge Y. Applied Optimization. Editor: Springer Book. 2005: 1-339.

[23] Serdar K, Serkan B. An Improved Vogel's Approximation Method for the Transportation Problem. Mathematical and Computational Applications. 2011; 16 (2): 370-381.

[24] Justice K A, Gideon K G, Gabriel O F. MATLAB Implementation of Vogel's Approximation and the Modified Distribution Methods. An international journal of advanced computer technology. 2015; 4 (1) : 1449-1453. 